\title{
STI perspectives
}

\author{
Joseph D Tucker (i) , ${ }^{1,2}$ Kristine Shields, ${ }^{3}$ Giovanni Villa (i) ${ }^{4}$
}

\section{TURNING TO THE CROWD FOR ADVICE ON STI DIAGNOSIS}

Do people turn to internet groups for help with their own sexual health problems? An empirical analysis of the online website Reddit examined how often people ask the online community for diagnostic help related to STIs. The study examined a random sample of 500 social media posts and found that $58 \%$ of posts requested diagnostic advice from the online community. A total of $87 \%$ of requests for help were answered by the local community, often within a matter of hours. The investigators did not examine the accuracy of responses or whether this online engagement delayed clinical care seeking. This study raises important questions about the opportunities and perils of tapping collective intelligence for sexual health.

Nobles AL, Leas EC, Althouse BM, et al. Requests for Diagnoses of Sexually Transmitted Diseases on a Social Media Platform. JAMA 2019;322(17):1712-3. doi:10.1001/jama.2019.14390.

\section{PRIMARY CARE INTERVENTION INCREASES STI TESTING RATES IN REMOTE POPULATIONS}

Australian Aboriginal communities have a high burden of STIs and are often neglected in public health responses. ${ }^{1} \mathrm{~A}$ randomised trial evaluated the impact of a quality improvement intervention among 68 primary care centres serving remote areas of Australia. For each cluster of care centres, the intervention phase comprised cycles of reviewing clinical data and modifying systems to support improved STI clinical practice. The primary outcomes were community prevalence and testing coverage of gonorrhoea, chlamydia and trichomonas among 16-34 year-old residents. The trial compared these outcomes between an intervention and a standard of care period over a total of 3 years. Although the intervention did not impact

\footnotetext{
${ }^{1}$ IGHID, University of North Carolina, Chapel Hill, North Carolina, USA

${ }^{2}$ Faculty of Infectious and Tropical Diseases, London School of Hygiene and Tropical Medicine, London, UK ${ }^{3}$ Shields' Medical Writing and Consulting, Philadelphia, Pennsylvania, USA

${ }^{4}$ Department of Global Health and Infection, Brighton and Sussex Medical School, Brighton, UK
}

Correspondence to Dr Joseph D Tucker, UNC ProjectChina, Guangzhou 510095, China; jdtucker@med.unc. edu
STI prevalence, testing rates increased from $16 \%$ during the standard of care to $22 \%$ during the intervention period. The findings demonstrate that comprehensive quality improvement interventions are feasible in under-served communities.

Ward J, Guy RJ, Rumbold AR, et al. Strategies to improve control of sexually transmissible infections in remote Australian Aboriginal communities: a steppedwedge, cluster-randomised trial. Lancet Glob Health 2019;7(11):e1553-e63. https://doi.org/10.1016/S2214-109X(19) 30411-5.

\section{Programmatic offering of self-sampling increases uptake of STI testing and positive case finding}

Self-collected samples are as diagnostically accurate for STIs as clinician-collected samples and may reach a broader population. To investigate the impact of offering self-collection of samples, a systematic review pooled data from 11 studies, all from high-income countries, involving 202745 participants. Meta-analysis found that offering self-collection nearly tripled overall uptake of STI testing and doubled the finding of positive cases. While a lower proportion of positive test results was found in self-collected samples, perhaps due to symptomatic, high-risk individuals choosing traditional clinical testing, overall positive case finding increased due to the higher number of participants willing to be tested. Research in lowincome and middle-income countries, where the need is greatest, is warranted.

Ogale Y, Yeh PT, Kennedy CE, et al. Self-collection of samples as an additional approach to deliver testing services for sexually transmitted infections: a systematic review and meta-analysis. BMJ Glob Health 2019;4:e001349. doi:10.1136/ bmjgh-2018-001349.

\section{PROPHYLACTIC ZIKA VACCINATION OF AT-RISK WOMEN CAN BE COST- EFFECTIVE FOR COUNTRIES IN THE AMERICAS}

The long-term sequelae of Zika virus infections cause substantial economic burden. Researchers evaluated the potential cost-effectiveness of implementing a single-dose vaccination programme for at-risk women in 18 countries in the Americas where Aedes aegypti mosquitos are abundant. Factors included in the simulation model were vector and sexual transmission, fertility rates and age and sex distributions, along with shortterm and long-term medical costs from Guillain-Barre syndrome in adults and microcephaly in infants. Comparing scenarios in the presence and absence of vaccination found that vaccines with efficacy as low as $60 \%$ could substantially reduce incidence of microcephaly. When simulating attack rates plus or minus $4 \%$ from the 2015-2017 baseline, the analyses showed that introducing a routine vaccination programme would be cost-saving for all countries studied.

Shoukat A, Vilches T, Moghadas SM. Cost-effectiveness of prophylactic Zika virus vaccine in the Americas. Emerging Infectious Diseases 2019;25(12):219196. doi:10.3201/eid2512.181324.

\section{Condoms and anal sex: has the time for a label indication finally come?}

While both antiretroviral therapy and the scale-up of pre-exposure prophylaxis (PrEP) have demonstrated ability to abate HIV transmission via condomless anal sex, ${ }^{2}{ }^{3}$ condoms remain the key prophylactic intervention against other STIs. However, to date condoms have a label indication limited to vaginal sex. In a crossover trial, 252 men who have sex with men (MSM) and 252 men who have sex with women (MSW) were provided with condoms and asked to complete a daily coital diary, which included type of sex, lubricant and condom use and condom slippage or breakage. Across all condom types, failure was low (1.3\%) and lower in MSM (0.7\%) relative to MSW (1.9\%); use of lubricant reduced the risk of condom failure in both anal and vaginal acts. The findings pave the way to extending the label indication of condoms to anal sex.

Siegler J, Rosenthal ET, Sullivan P, et al. Levels of clinical condom failure for anal sex: A randomized cross-over trial. eClinicalMedicine 2019;17:100199. doi:https:// doi.org/10.1016/j.eclinm.2019.10.012.

\section{HIV RESISTANCE TO PREP AGENTS AND INTEGRASE INHIBITORS IN A SELECTED POPULATION OF MSM IN THE USA}

Investigators analysed the drug resistance profiles of 142 MSM living with HIV of predominantly black ethnicity who had screened for participation in the HIV Prevention Trials Network (HPTN) 078 study $^{4}$ and had a viral load $\geq 1000$ copies $/ \mathrm{mL}$, including both treated and untreated individuals. By conventional sequencing, almost a third showed 
mutations affecting $\geq 1$ antiretroviral drug class, most commonly the nonnucleoside reverse transcriptase inhibitors (NNRTIs) (21\%) and the nucleoside reverse transcriptase inhibitor (NRTIs) (16\%), whereas resistance to protease inhibitors was less prevalent (3.5\%). Sixteen per cent had resistance to PrEP agents (tenofovir disoproxil fumarate (TDF), lamivudine (3TC), emtricitabine (FTC)). At 8.0\%, mutations affecting the integrase inhibitors were more prevalent than expected and included a subset with predicted intermediate resistance to second-generation agents (dolutegravir, bictegravir). These sobering data require confirmation in larger surveys. Meanwhile, the potential transmission of resistance to PrEP agents and integrase inhibitors should be considered in some at-risk populations.
Fogel J, Sivay M, Cummings V, et al. HIV drug resistance in a cohort of HIV-infected MSM in the United States. 2020 AIDS;34:91-101. doi:10.1097/ QAD.0000000000002394.

Handling editor Anna Maria Geretti

Contributors The first draft came from all three authors. We each focused on two of the sections. All authors read and approved the final version.

Competing interests None declared.

Provenance and peer review Commissioned; internally peer reviewed.

(c) Author(s) (or their employer(s)) 2020. No commercial re-use. See rights and permissions. Published by BMJ.

\section{(A) Check for updates}

To cite Tucker JD, Shields K, Villa G. Sex Transm Infect 2020;96:313-314.

Sex Transm Infect 2020;96:313-314. doi:10.1136/sextrans-2019-054272
ORCID iDs

Joseph D Tucker http://orcid.org/0000-0003-2804-1181 Giovanni Villa http://orcid.org/0000-0001-6747-9851

\section{REFERENCES}

1 Ward J, Wand H, Bryant J, et al. Prevalence and correlates of a diagnosis of sexually transmitted infection among young Aboriginal and Torres Strait Islander people: a national survey. Sex Transm Dis 2016;43:177-84.

2 Rodger AJ, Cambiano V, Bruun T, et al. Risk of HIV transmission through condomless sex in serodifferent gay couples with the HIV-positive partner taking suppressive antiretroviral therapy (partner): final results of a multicentre, prospective, observational study. Lancet 2019;393:2428-38.

3 McCormack S, Dunn DT, Desai M, et al. Pre-Exposure prophylaxis to prevent the acquisition of HIV-1 infection (PROUD): effectiveness results from the pilot phase of a pragmatic open-label randomised trial. Lancet 2016;387:53-60.

4 Chen I, Connor MB, Clarke W, et al. Antiretroviral drug use and HIV drug resistance among HIV-infected black men who have sex with men: HIV prevention trials network 061. J Acquir Immune Defic Syndr 2015;69:446-52. 